\title{
Article \\ A Facile Synthesis of Noble-Metal-Free Catalyst Based on Nitrogen Doped Graphene Oxide for Oxygen Reduction Reaction
}

\author{
Vladimir P. Vasiliev ${ }^{1, * \mathbb{D}}$, Roman A. Manzhos ${ }^{1} \mathbb{D}$, Valeriy K. Kochergin ${ }^{1}$, Alexander G. Krivenko ${ }^{1}$, \\ Eugene N. Kabachkov ${ }^{1,2}{ }^{\mathbb{D}}$, Alexander V. Kulikov ${ }^{1}$, Yury M. Shulga ${ }^{1} \mathbb{D}$ and Gennady L. Gutsev ${ }^{3, *}$ \\ 1 Institute of Problems of Chemical Physics of RAS, Acad. Semenov ave. 1, 142432 Chernogolovka, Russia; \\ rmanzhos@yandex.ru (R.A.M.); kocherginvk@yandex.ru (V.K.K.); krivenko@icp.ac.ru (A.G.K.); \\ en.kabachkov@gmail.com (E.N.K.); kulav@icp.ac.ru (A.V.K.); yshulga@gmail.com (Y.M.S.) \\ 2 Chernogolovka Scientific Center, Russian Academy of Sciences, 142432 Chernogolovka, Russia \\ 3 Department of Physics, Florida A\&M University, Tallahassee, FL 32307, USA \\ * Correspondence: vpvasiliev@mail.ru (V.P.V.); gennady.gutsev@famu.edu (G.L.G.)
}

Citation: Vasiliev, V.P.; Manzhos, R.A.; Kochergin, V.K.; Krivenko, A.G.; Kabachkov, E.N.; Kulikov, A.V.; Shulga, Y.M.; Gutsev, G.L. A Facile Synthesis of Noble-Metal-Free Catalyst Based on Nitrogen Doped Graphene Oxide for Oxygen Reduction Reaction. Materials 2022, 15, 821. https://doi.org/10.3390/ ma15030821

Academic Editors: Victoria Samanidou and Eleni Deliyanni

Received: 15 December 2021 Accepted: 18 January 2022

Published: 21 January 2022

Publisher's Note: MDPI stays neutral with regard to jurisdictional claims in published maps and institutional affiliations.

Copyright: () 2022 by the authors Licensee MDPI, Basel, Switzerland. This article is an open access article distributed under the terms and conditions of the Creative Commons Attribution (CC BY) license (https:// creativecommons.org/licenses/by/ $4.0 /)$.

\begin{abstract}
A simple method for the mechanochemical synthesis of an effective metal-free electrocatalyst for the oxygen reduction reaction was demonstrated. A nitrogen-doped carbon material was obtained by grinding a mixture of graphene oxide and melamine in a planetary ball mill. The resulting material was characterized by XPS, EPR, and Raman and IR spectroscopy. The nitrogen concentration on the N-bmGO surface was 5.5 at.\%. The nitrogen-enriched graphene material (NbmGO has half-wave potential of $-0.175 /-0.09 \mathrm{~V}$ and was shown to possess high activity as an electrocatalyst for oxygen reduction reaction. The electrocatalytic activity of $\mathrm{NbmGO}$ can be associated with a high concentration of active sites for the adsorption of oxygen molecules on its surface. The high current retention ( $93 \%$ for $12 \mathrm{~h}$ ) after continuous polarization demonstrates the excellent long-term stability of $\mathrm{NbmGO}$.
\end{abstract}

Keywords: oxygen reduction reaction; noble-metal-free catalysts; graphene oxide; melamine; ball-milling; N-doped

\section{Introduction}

Fuel cells are considered as promising, renewable, and environmentally friendly energy sources. For the widespread use of fuel cells, however, it is necessary to solve several problems, one of which is related with fabrication of proper catalysts. Currently, in fuel cells with polymer electrolyte membranes, the active component of cathodic catalysts is presented by nanoparticles composed of platinum or its alloys which are deposited on carbon black [1-3]. Catalysts of this type have both advantages such as complete oxygen reduction and low overvoltage and obvious and fundamentally inevitable disadvantages such as sensitivity to impurities, high cost, limited resources, and low oxygen reduction reaction rates (ORR). It should be noted that the latter property restricts the load characteristics of fuel cells based on such catalysts [4-6]. One of the directions of research in the creation of ORR catalysts is the use of various types of carbon nanoforms (graphene-like structures, nanotubes, fullerenes, etc.) as carriers for Pt and its alloys. Another direction of research is based on the development of simple and effective methods for modifying the carbon structures themselves to create on their basis metal-free catalysts for the oxygen electroreduction in fuel cells.

Carbon nanostructures doped with $p$-elements are considered to be promising electrocatalysts for the oxygen reduction reaction $[1,7,8]$. The catalytic characteristics of modified graphene-like structures, for example, with nitrogen, are due to ability of their atoms to form a delocalized conjugated system with $\mathrm{sp}^{2}$-hybridized carbon, where a common 
positive charge on atoms of the carbon frame adjacent to nitrogen is created $[9,10]$. Note that in order to increase the productivity of catalysts based on graphene structures, it is necessary to increase the specific concentration of active ORR centers on the electrode surface accessible to electrolyte.

It was shown in many studies (see, for example, $[8,11,12]$ ), that the oxygen reduction reaction proceeds on such structures according to the four-electron mechanism, which was previously considered $[13,14]$ to be characteristic only for platinum and platinum alloy catalysts. The production of nitrogen-doped carbon nanoform using standard methods is complicated by the possible toxicity of nitrogen precursors and their contamination of the final products as well as by the necessity to use expensive specialized equipment is required. Therefore, the development of non-standard methods for obtaining doped graphene-based catalysts presents an important task. In particular, a mechanochemical approach can be used since it allows doping of graphene structures with nitrogen atoms to be performed. In our case, it allows to create active ORR centers distributed over highly dispersed material. In other words, there is an increased electrode surface available for electrolyte. It should be noted that particles of such materials are less susceptible to agglomeration, in contrast to hydrophobic graphene sheets, which should contribute to a higher temporal stability of the electrocatalytic characteristics of such catalysts.

In the present work, we proposed a strategy for a simple one-step solid-state synthesis of nitrogen-enriched carbon powder (NbmGO) using inexpensive industrial precursors, namely graphene oxide (GO) and melamine. The synthesized material was characterized by methods of scanning electron microscopy, X-ray photoelectron spectroscopy, and infrared and Raman spectroscopies. In addition, $\mathrm{NbmGO}$ was tested as an ORR electrocatalyst and showed a higher efficiency (a decrease in ORR overvoltage and an increase in the contribution of complete oxygen reduction to water in the overall process) compared to the results obtained previously [15]. It should be noted that the number of studies on the synthesis of carbon materials and their modification using solid-phase methods is quite scarce, and restricted to the splitting of graphite [16,17] and the preparation of composites of carbon materials with transition metal oxides [18,19].

\section{Experimental}

\subsection{Synthesis of Nitrogen-Doped Carbon Material}

Graphene oxide was synthesized using a modified Hammers method [20] with chemical composition $\mathrm{C}_{8} \mathrm{O}_{4.6} \mathrm{H}_{1.8}\left(\mathrm{H}_{2} \mathrm{O}\right)_{0.58}$ and density $\sim 1.2 \mathrm{~g} / \mathrm{cm}^{3}$. Melamine $\mathrm{C}_{3} \mathrm{~N}_{6} \mathrm{H}_{6}(99.9 \%$, BASF SE, Mannheim, Germany) was used as a source of nitrogen (for details, see the Supplementary Materials). The mechanochemical synthesis was carried out in a FRITSCH pulverisette- 6 planetary mill with a grinding vessel and balls made of $\mathrm{ZrO}_{2}$. The internal diameter of the grinding vessel, the volume, and the ball diameter were $65 \mathrm{~mm}, 85 \mathrm{~mL}$, and $5 \mathrm{~mm}$, respectively. The GO/melamine ratio of reagents was $4: 1$, rotation speed was $400 \mathrm{rpm}$, and grinding time was $6 \mathrm{~min}$. After grinding, the resulting powder was kept for $1 \mathrm{~h}$ in a $10 \%$ aqueous solution of ammonia, treated in an ultrasonic bath, and then it was centrifuged and washed with water 4-5 times to remove melamine residues.

\subsection{Characterization}

The sample images were acquired using a Zeiss LEO SUPRA-25 scanning electron microscope (Jena, Germany), and Raman spectra were recorded using a Bruker Senterra spectrometer Billerica, Billerica, MA, USA). The laser radiation wavelength was $532 \mathrm{~nm}$, the radiation power at the measurement point was $1 \mathrm{~mW}$, and the diameter of the analyzing laser beam was $\sim 1 \mu \mathrm{m}$. Infrared spectra of the powders were obtained using an FT-IR VERTEX 70v spectrometer (Billerica, MA, USA) in vacuum (50 scans with the resolution of $\left.4 \mathrm{~cm}^{-1}\right)$.

XPS spectra were obtained with the use of an electronic spectrometer for chemical analysis Specs PHOIBOS 150 MCD (Berlin, Germany). When recording the spectra, the vacuum in the spectrometer chamber did not exceed $2 \times 10^{-10}$ Torr; the X-ray tube was 
equipped with a magnesium anode $(\mathrm{Mg} \mathrm{K} \alpha$ radiation is $1253.6 \mathrm{eV})$ and the source power was $225 \mathrm{~W}$. The survey spectrum was recorded in the range $0-1000 \mathrm{eV}$ in the constant transmission energy mode ( $40 \mathrm{eV}$ for the survey spectrum and $10 \mathrm{eV}$ for individual lines). The survey spectrum was recorded with a step of $1 \mathrm{eV}$, while the spectra with individual lines with a step of $0.05 \mathrm{eV}$.

The ESR spectra of the powders were recorded at room temperature with a Bruker Elexsys II E 500 EPR spectrometer (Billerica, MA, USA) and an SE/X 2544 radio spectrometer (Radiopan, Poznan, Poland). The number of spins $N$ and the $g$-factor were determined using the Xepr software package. To check the correctness of these procedures, a weighed quantity of $\mathrm{CuSO}_{4} \times 5 \mathrm{H}_{2} \mathrm{O}$ and a DPPH sample with a $g$-factor of 2.0036 were used. The accuracy of concentration determination was $\sim 15 \%$. The electronic absorption spectra were obtained using a spectrophotometer PE-5400uf (Orenburg, Russia) and a Shimadzu UV3101PC. The conductivity of the sample films was recorded on a potentiostat P-20X Elins (Orenburg, Russia) using a Micru XIDE1 thin-film Au-interdigitated electrode (90 pairs, 10/10 $\mu \mathrm{m}$, electrode/gap).

\subsection{Electrochemical Measurements}

Voltammograms with linear potential sweep were measured in a three-electrode cell on a setup with the RRDE-3A rotating disk electrode s (ALS Co., Ltd., Naka-ku Sakai, Japan) using a potentiostat Autolab PGSTAT 302N (Metrohm Autolab, Utrecht, Holland) in an oxygen-saturated $0.1 \mathrm{M} \mathrm{KOH}$ solution with a potential sweep rate of $v=10 \mathrm{mV} / \mathrm{s}$ at electrode rotation frequencies $\omega=360-6400 \mathrm{rpm}$. The current-voltage curves were analyzed using the Koutetsky-Levich equation [21]:

$$
\begin{gathered}
\frac{1}{j}=\frac{1}{j_{\mathrm{k}}}+\frac{1}{j_{\mathrm{d}}} \\
j_{\mathrm{k}}=n \mathrm{~F} k c^{0} \\
j_{\mathrm{d}}=0.62 n \mathrm{FD}^{2 / 3} \omega^{1 / 2} v^{-1 / 6} c^{0}
\end{gathered}
$$

where $j_{\mathrm{k}}$ is the density of kinetic current, $j_{\mathrm{d}}$ is the density of limiting diffusion current, $\mathrm{F}$ is the Faraday number $(\mathrm{F}=96,485 \mathrm{C} / \mathrm{mol}), n$ is the number of electrons participating in the electrode reaction, $\mathrm{D}$ is the coefficient of oxygen diffusion in a $0.1 \mathrm{M} \mathrm{KOH}$ solution $\left(\mathrm{D}=1.9 \times 10^{-5} \mathrm{~cm}^{2} / \mathrm{s}\right), v$ is the kinematic viscosity of a $0.1 \mathrm{M} \mathrm{KOH}$ solution $\left(v=0.01 \mathrm{~cm}^{2} / \mathrm{s}\right)$, and $c^{0}$ is the volume concentration of dissolved oxygen $\left(c^{0}=1.2 \mathrm{mM}\right.$ in a $0.1 \mathrm{M} \mathrm{KOH}$ solution) $[9,22]$.

A glassy carbon (GC) disk with a diameter of $3 \mathrm{~mm}$, pressed into a PEEK polymer (ALS Co., Ltd., Naka-ku Sakai, Japan), served as a working electrode. The electrode surface was preliminarily polished with $1 \mu \mathrm{m} \mathrm{Al}_{2} \mathrm{O}_{3}$ powder, then a drop of an aqueous suspension of bmGO or $\mathrm{NbmGO}$ with a volume of $\sim 6 \mu \mathrm{L}$ and a concentration of $1 \mathrm{mg} / \mathrm{mL}$, containing $0.01 \mathrm{wt} \%$ Nafion, was applied and dried at room temperature. A platinum wire with an area of $\sim 1 \mathrm{~cm}^{2}$ was used as an auxiliary electrode and an $\mathrm{Ag} / \mathrm{AgCl}$ electrode filled with a saturated $\mathrm{KCl}$ solution was used as a reference electrode. All potentials $(E)$ are given on the scale of the reference electrode. The bmGO deposited on the GC electrode was preliminarily electrochemically reduced during potential cycling (20-50 cycles) in an $\mathrm{O}_{2}$-saturated $0.1 \mathrm{M}$ $\mathrm{KOH}$ solution in the $E$ range from $50 \mathrm{mV}$ to $-1300 \mathrm{mV}$ at a potential sweep rate of $50 \mathrm{mV} / \mathrm{s}$. The catalyst stability was tested using chronoamperometry method at $-250 \mathrm{mV}$ for $12 \mathrm{~h}$.

\section{Results and Discussions}

\subsection{Structural Characterization of bmGO and $\mathrm{NbmGO}$}

\subsubsection{SEM}

Figure 1 shows SEM images of samples of the starting graphene oxide (GO), ball milled graphene oxide (bmGO), and nitrogen-enriched carbon material ( $\mathrm{NbmGO}$ ) obtained by processing a mixture of GO and melamine in a ball mill. As can be seen from the figure, highly dispersed materials with a size of visible aggregates not exceeding $50 \mathrm{~nm}$ were 
formed by processing in the ball mill. This process increases the effective surface of the electrode accessible for electrolyte, and only small fragments of the original GO sheets can be observed in Figure 1b,c.
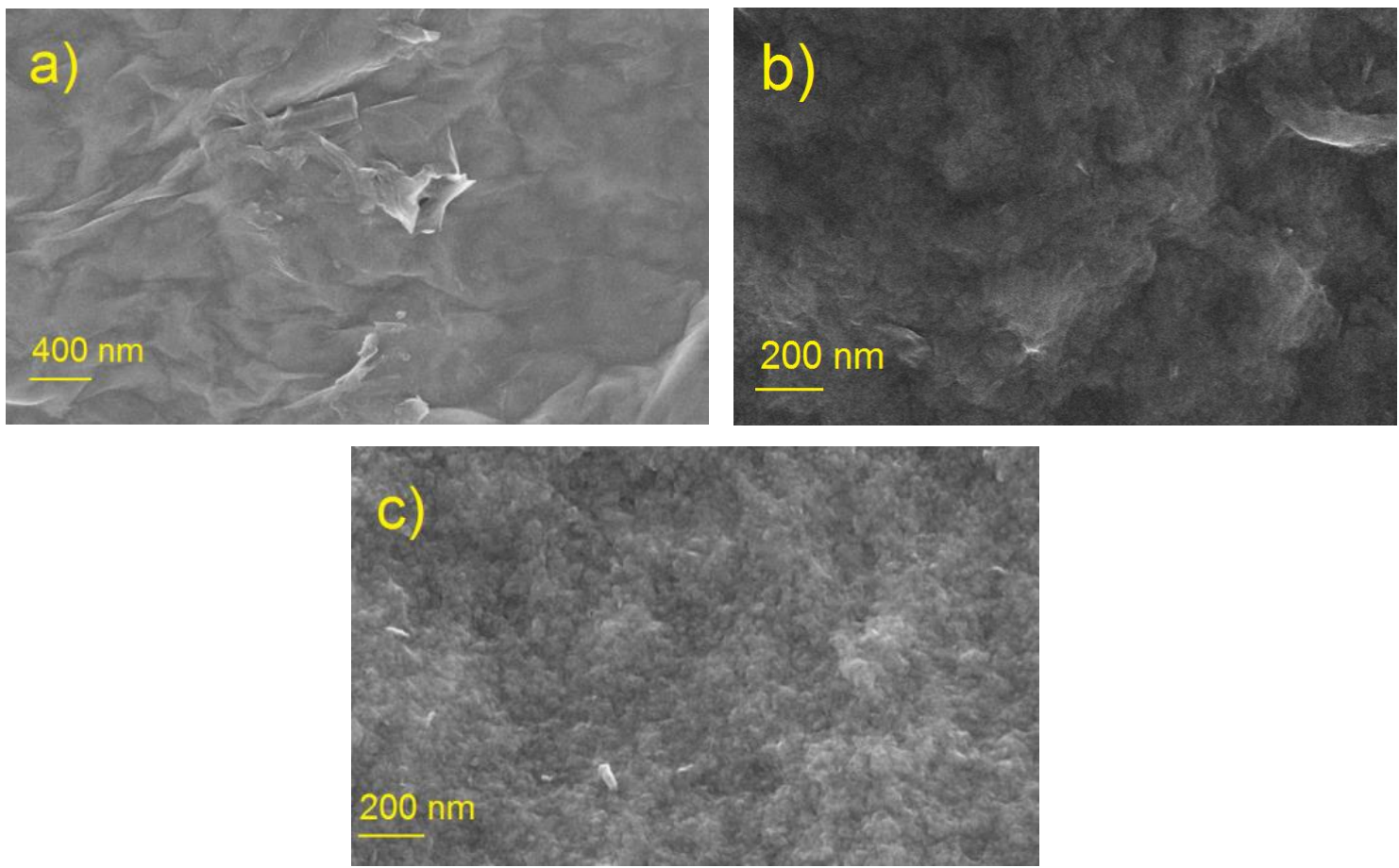

Figure 1. SEM images of GO (a), bmGO (b), and $\mathrm{NbmGO}$ (c).

The elemental composition of carbon materials was calculated using analytical lines of the survey XPS spectrum (Figure S1 of the Supplementary Materials). The oxygen concentration decreases markedly only for the $\mathrm{NbmGO}$ sample. The recovery of the sample is accompanied by an increase in the nitrogen content up to 5.5 at.\% (Table S1 of the Supplementary Materials). The relative concentration of carbon in the $\mathrm{NbmGO}$ and bmGO samples increases insignificantly, by only $2.4-2.5$ at.\%. Although parent GO is an insulator, significant electronic conduction occurs in the films of the bmGO and NbmGO samples (Figure S2 of the Supplementary Materials).

\subsubsection{XPS}

The shape of the $\mathrm{C} 1 \mathrm{~s}$ line in the spectra of the samples under study and the line fitting with four symmetrical Gaussian-Lorentz curves are presented in Figure 2a-c. The position of the main most intense peak (C1) is typical for $s p^{2}$-carbon materials (Table S2 of the Supplementary Materials). The second most intense peak (C2) refers to carbon atoms that singly bonded with a nitrogen or oxygen atom of a hydroxyl $(\mathrm{C}-\mathrm{OH})$ or epoxy groups. The third peak (C3) can be attributed to the carbon atoms having two bonds with the oxygen atom $(\mathrm{C}=\mathrm{O}$ or $\mathrm{O}-\mathrm{C}-\mathrm{O})$. The last peak $(\mathrm{C} 4)$ was assigned to the carbon atoms of the carboxyl groups $(\mathrm{O}-\mathrm{C}=\mathrm{O})$ [23]. Note that the assignment of individual peaks was done in accordance with recommendations in [24].

According to the previous studies $[8,25]$, nitrogen in a graphite-like matrix can be found in four or five configurations: pyridinic (N1, six-membered ring), pyrrolic (N2, five-membered ring), graphitic (N3/N4), and oxidized pyridinic (N5) (see Figure S3 in the Supplementary Materials). The pyridinic and pyrrolic nitrogen atoms are located at the edges of a graphene sheet or at the defect sites. Nitrogen atoms of the N3 and N4 types replace carbon atoms in the graphite structure and differ by the location type. The nitrogen atom scan be located at the edges of a graphene sheet (N3) or in its center (N4). Nitrogen, which is a part of cyano and amino groups, may also be present [26]. 

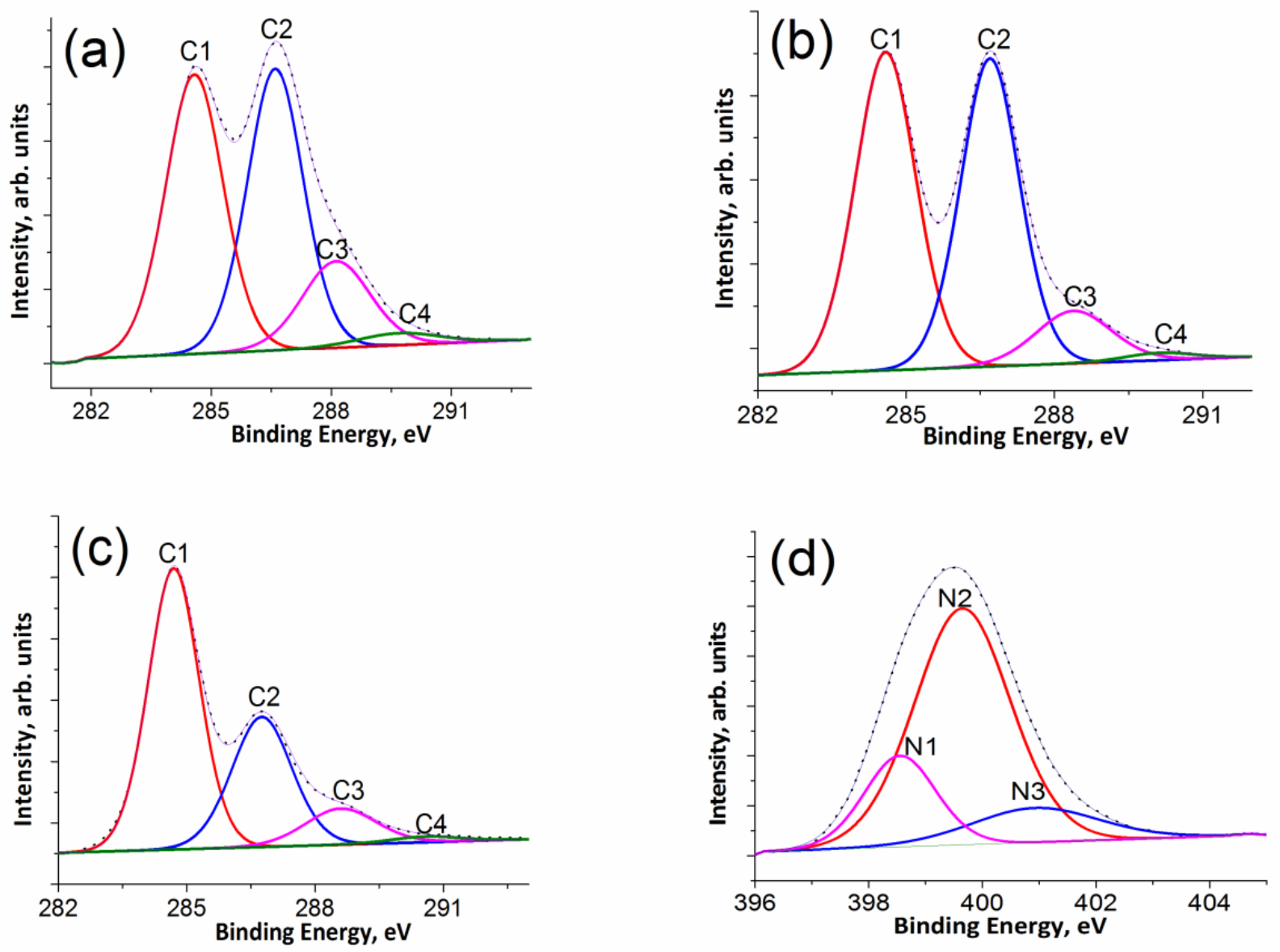

Figure 2. $\mathrm{C} 1 \mathrm{~s}$ lines in the XPS spectra of $\mathrm{GO}(\mathbf{a}), \mathrm{bmGO}(\mathbf{b}), \mathrm{NbmGO}(\mathbf{c})$, and $\mathrm{N} 1 \mathrm{~s}$ lines of $\mathrm{NbmGO}(\mathbf{d})$.

The identification of surface nitrogen-containing groups can be carried out on the basis of an analysis of the fine structure of the N1s line in the high resolution XPS spectrum. According to the literature (see, e.g., [8,25] and references therein), pyridine nitrogen (N1) appears in the range 398.0-399.3 eV and pyrrole nitrogen (N2) appear in the range 399.8 $401.2 \mathrm{eV}$ ) in the XPS spectra of nitrogen-doped carbon materials. It is worth noting that the N1s lines of amino (399.1 eV [25]) and cyano (399.3 eV [25]) groups are also located in this region; therefore, it is difficult to clearly identify it. The peak corresponding to the nitrogen atoms of the $\mathrm{N} 4$ type (inside a graphite sheet) is located at about $401 \mathrm{eV}$, and the peak corresponding to terminal graphite nitrogen (N3) is at $402.3 \mathrm{eV}$. Oxidized pyridine nitrogen (N5) corresponds to a peak at $402.8 \mathrm{eV}$ while pyrrole nitrogen (N2) corresponds to a peak at $404.7 \mathrm{eV}$ [25].

Three peaks can be distinguished in the N1s line of the NbmGO sample (see Figure 2d). When assigning these peaks, we came to a quite unexpected conclusion that the major contribution to the N1s line comes from the nitrogen atoms of the pyrrolic (N2) nitrogen. It is interesting to note that it was concluded in a model catalyst study that pyridinic nitrogen in graphite structures creates active centers for the oxygen reduction reaction [27].

\subsubsection{FTIR}

The FTIR spectra of melamine, initial graphene oxide, bmGO, and $\mathrm{NbmGO}$ are shown in Figure 3. It can be seen in the Figure that the IR spectrum of NbmGO differs from the IR spectra of the starting materials. Thus, absorption bands of stretching vibrations of $\mathrm{N}-\mathrm{H}$ bonds, whose maxima in the spectrum of pure melamine are located at 3468, 3417, 3324, and $3121 \mathrm{~cm}^{-1}$, are lacking in the NbmGO spectrum. At the same time, the spectrum of $\mathrm{NbmGO}$ has absorption bands, which can be attributed to stretching vibrations of cyano 
groups in different environments (the region from 2350 to $1900 \mathrm{~cm}^{-1}$ ). Comparing the spectrum of $\mathrm{NbmGO}$ with the spectra of GO and bmGO, one can note that the absorption band due to the stretching $\mathrm{C}=\mathrm{O}$ vibrations is practically absent in the NbmGO spectrum. Furthermore, one can notice a significant increase in the intensity of the absorption band associated with the vibrations of the $\mathrm{C}=\mathrm{C}$ double bonds forbidden in the IR spectrum. According to the literature data, the band at $1360-1370 \mathrm{~cm}^{-1}$ can be attributed to vibrations of the $\mathrm{C}-\mathrm{OH}$ bond, and the band at $1220 \mathrm{~cm}^{-1}$ corresponds to vibrations of $\mathrm{C}-\mathrm{O}-\mathrm{C}$ bonds. The band at $1060 \mathrm{~cm}^{-1}$ is attributed to the vibrations of alkoxy groups [28] (See Table S5 in the Supplementary Materials).

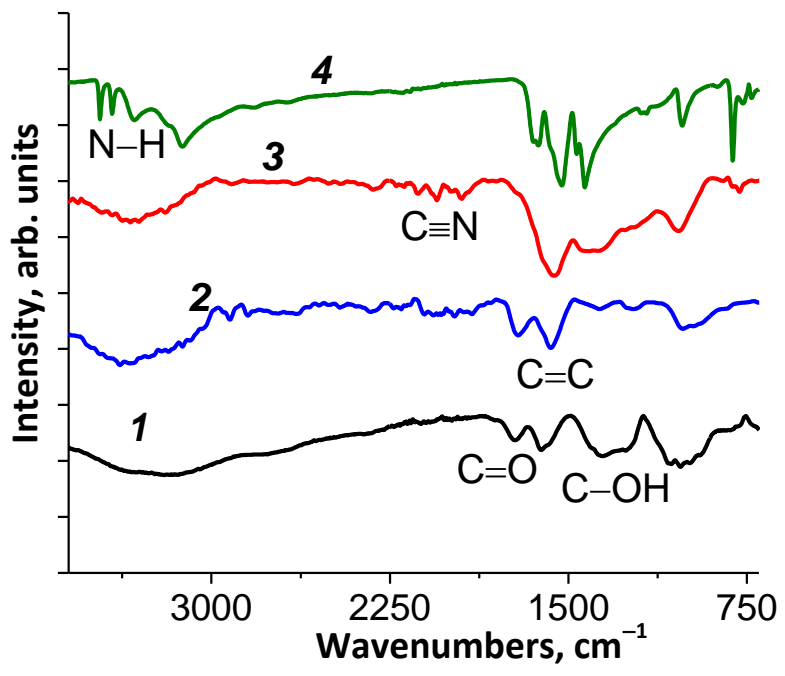

Figure 3. FTIR spectra of GO (1), bmGO (2), NbmGO (3), and melamine (4).

\subsubsection{Raman}

The Raman spectra of the samples studied are shown in Figure 4. The spectra contain peaks designated as D, G, and 2D. It is well known that the 2D peak for single-layer graphene is a narrow peak, whose intensity exceeds the intensity of peak $\mathrm{G}$. In the case of two-layer graphene, the intensity of the 2D peak decreases, while its half-width increases [29]. When the number of layers in graphene becomes more than five, the 2D peak disappears.

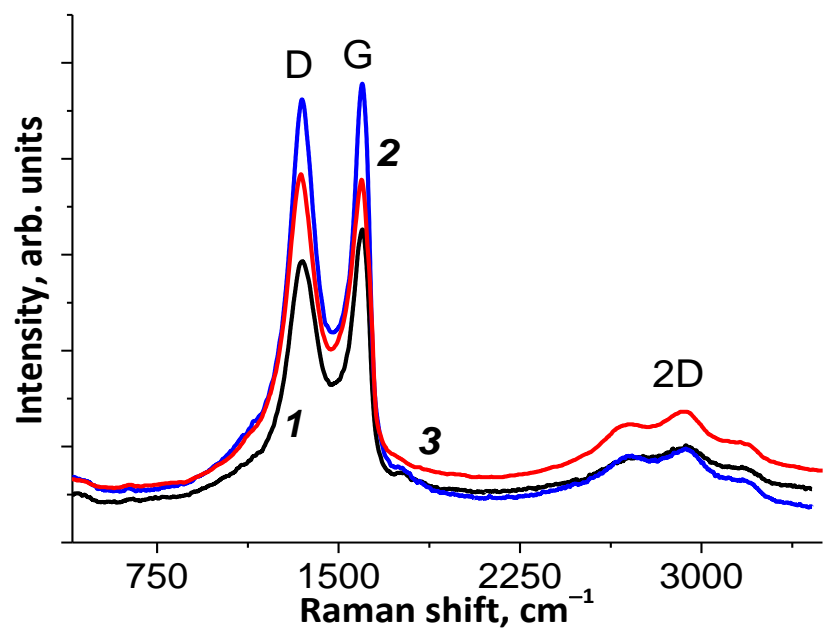

Figure 4. Raman spectra of GO (1), bmGO (2), and NbmGO (3). See the text for the peak designation.

The presence of a $2 \mathrm{D}$ peak in the Raman spectra of our samples means that there are few-layer graphene-like structures. In addition, note the shift in the position of the $\mathrm{G}$ peak towards lower values in the $\mathrm{GO} \rightarrow \mathrm{bmGO} \rightarrow \mathrm{NbmGO}$ series (see Table $\mathrm{S} 3$ of the 
Supplementary Materials). A shift in the position of the $G$ peak towards lower values during GO milling was also observed previously [30].

The ratio of the $\mathrm{D}$ and $\mathrm{G}$ band intensities $\left(\mathrm{I}_{\mathrm{D}} / \mathrm{I}_{\mathrm{G}}\right)$ can be used to estimate the size of the $\mathrm{sp}^{2}$ domains of $L_{\mathrm{a}}$ in the basal plane [31]:

$$
L_{\mathrm{a}}=\left(2.4 \times 10^{-10}\right) \lambda^{4}\left(I_{\mathrm{D}} / I_{\mathrm{G}}\right)^{-1}
$$

Based on the ratio of the D/G peak intensities (see Table S3 of the Supplementary Materials), the size of $s p^{2}$ domains is $19 \mathrm{~nm}$ (NbmGO), $20 \mathrm{~nm}$ (bmGO), and $22 \mathrm{~nm}$ (GO). Thus, milling leads to a slight increase in the number of defects and a decrease in the size of $s p^{2}$ domains. The insertion of nitrogen atoms into the graphene oxide lattice also increases the number of defects and decreases the size of the graphene $s p^{2}$ domains.

\subsubsection{ESR}

The ESR spectra obtained for the samples under study are presented in Figure 5. As can be seen in the figure, the ESR spectra of all samples contains narrow singlet lines. The $g$ factors of all samples are close to 2.0, which is typical for radicals where unpaired electrons of aromatic rings composed of carbon atoms occupy localized $\pi$-states [32,33].

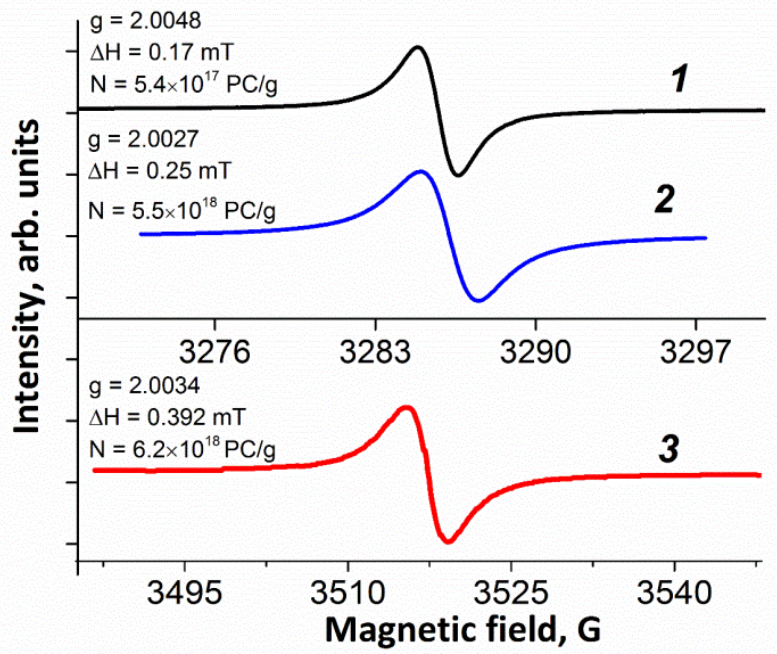

Figure 5. ESR spectra of GO (1), bmGO (2), and NbmGO (3) obtained at room temperature.

The measured spin concentration (see Table S4 of the Supplementary Materials) for the NbmGO sample is $6.2 \times 10^{18} \mathrm{PC} / \mathrm{g}$, which is an order of magnitude higher than the concentration of the GO sample $\left(5.4 \times 10^{17} \mathrm{PC} / \mathrm{g}\right)$ and is approximately comparable to the spin concentration for the bmGO sample $\left(5.5 \times 10^{18} \mathrm{PC} / \mathrm{g}\right)$. This is an indication of a significantly larger number of defects on the surface of carbon structures of the samples processed in the planetary mill, which largely determines their electrocatalytic activity in ORR.

\subsection{Electrochemical Analysis}

The voltammogram dependencies obtained on the initial GC electrode and GC electrodes coated with bmGO and $\mathrm{NbmGO}$ in a $0.1 \mathrm{M} \mathrm{KOH}$ solution saturated with oxygen are shown in Figure 6a. To determine the number of electrons $n$ participating in the ORR (see Figure $6 \mathrm{~b}$ ), the $j$ and $E$ dependences were measured at different speeds of electrode rotation. Figure $6 \mathrm{c}$ shows a series of such voltammogram curves for NbmGO and Figure $6 \mathrm{~d}$ displays the dependence of $j$ on $\omega$ plotted in the Koutetsky-Levich coordinates. From the slope of the $j-\omega$ dependences, the values of $n$ were calculated at various values of $E$ (see Figure $6 \mathrm{~b}$ ). 

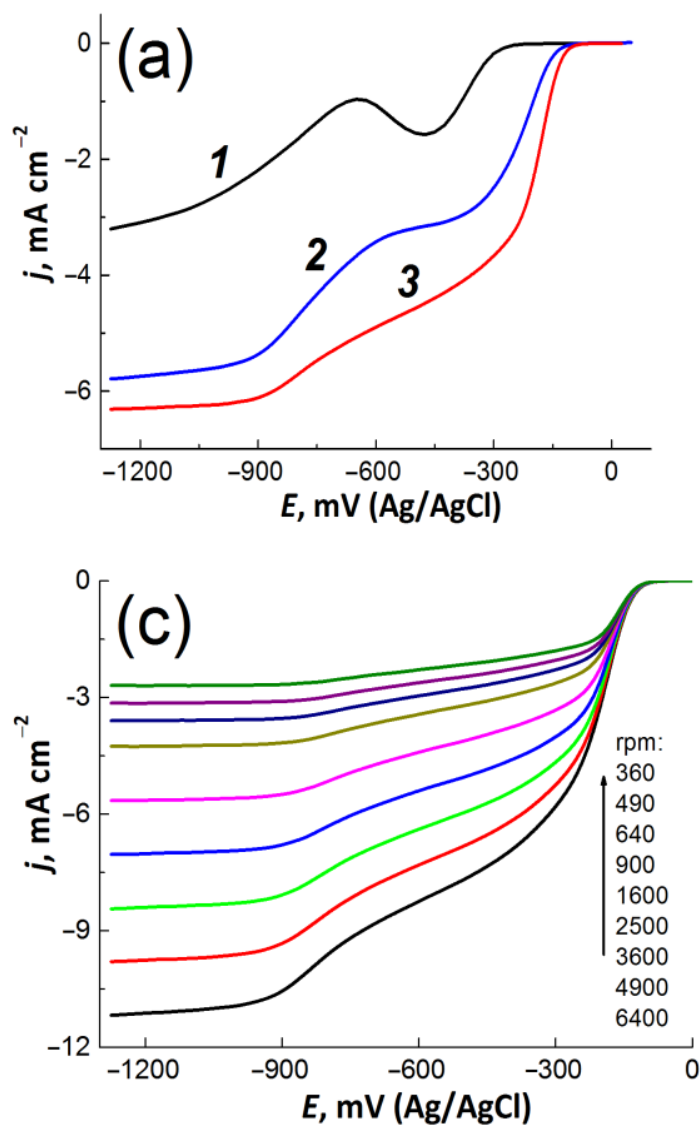
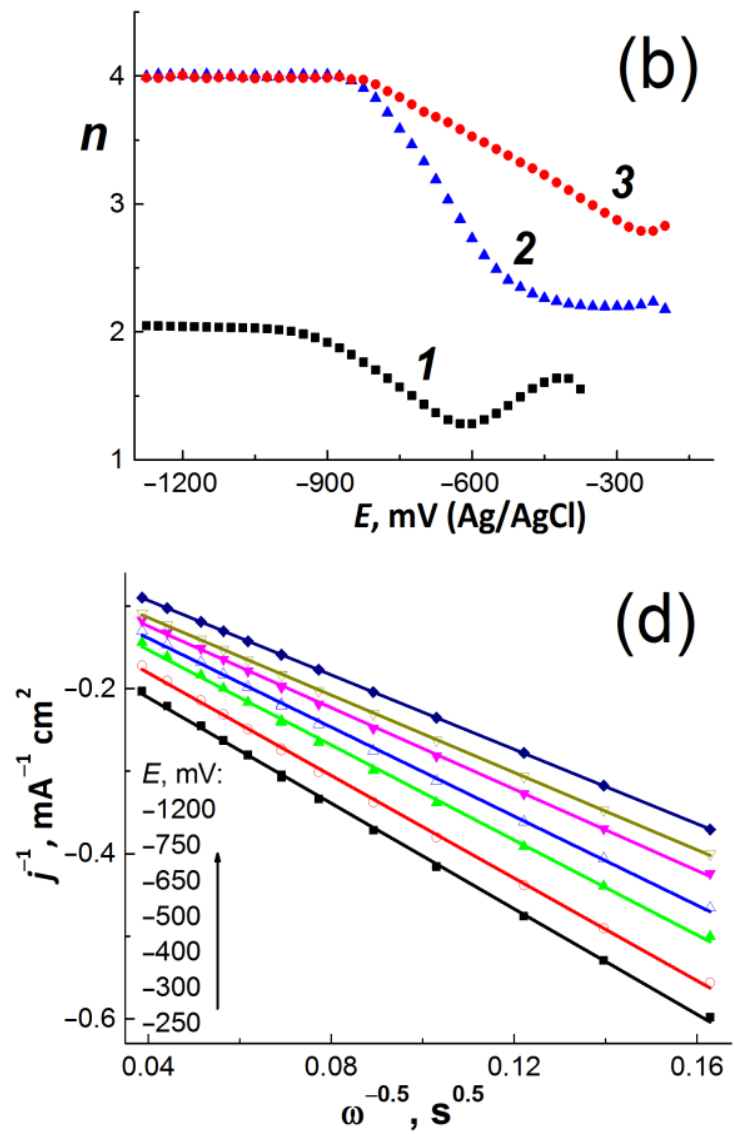

Figure 6. (a) Linear sweep voltammograms of $\mathrm{O}_{2}$-saturated $0.1 \mathrm{M} \mathrm{KOH}$ solution for the bare GC electrode (curve 1) and GC coated with bmGO (curve 2) and NbmGO (curve 3), $v=10 \mathrm{mV} / \mathrm{s}$, $\omega=2000 \mathrm{rpm}$. (b) Dependencies of the electron transfer number $n$ on the potential $\mathrm{E}$ for the bare GC electrode (curve 1), GC covered with bmGO (curve 2), and NbmGO (curve 3). (c) Voltammograms for NbmGO measured at different speed of electrode rotations. (d) Corresponding $j-\omega$ dependences in the Koutecký-Levich coordinates.

As can been seen from Figure 6a, the overpotential of the oxygen reduction reaction for bmGO and NbmGO significantly decreases compared to that of the initial GC. The half-wave potentials of the first oxygen reduction wave for $\mathrm{GC}, \mathrm{bmGO}$, and $\mathrm{NbmGO}$ are $-365 \mathrm{mV},-225 \mathrm{mV}$, and $-175 \mathrm{mV}$, respectively. In addition, an increase in the oxygen reduction current was observed when passing from the original GC electrode to the GC coated with bmGO and NbmGO.

On the voltammogram curve for bmGO (curve 2 in Figure 6a), two distinct waves which correspond to the predominant reduction of oxygen to hydrogen peroxide in the potential range from -250 to $-500 \mathrm{mV}(n \approx 2.2-2.3)$ and water at $\mathrm{E}<-850 \mathrm{mV}(n \approx 4)$ can be distinguished. In the case of $\mathrm{NbmGO}$ (curve 3 in Figure 6a), the first wave includes a segment of linear growth of the cathodic current of in the potential range from -400 to $-750 \mathrm{mV}$, while the second wave is characterized by reaching the limit at $\mathrm{E}<-900 \mathrm{mV}$ and corresponds to the limiting diffusion current of complete oxygen reduction to water. The corresponding value of the limiting diffusion current density calculated by using Equation (3) is $j_{\mathrm{d}}=-6.4 \mathrm{~m} / \mathrm{cm}^{2}$. It should be noted that there is also a linear increase in the number of electrons participating in the oxygen reduction reaction from 2.8 to 4.0 (Figure $6 \mathrm{~b}$ ) in the potential range from -250 to $-850 \mathrm{mV}$.

In the case of $\mathrm{NbmGO} \mathrm{O}_{2}$ is reduced to $\mathrm{H}_{2} \mathrm{O}(n \approx 2.8)$ even at low overpotentials $(E=-200 \mathrm{mV})$ in addition to its reduction to hydrogen peroxide with a gradual increase in the contribution of this process until the complete reduction of oxygen to water at 
$E<-850 \mathrm{mV}(n \approx 4)$. In general, bmGO and $\mathrm{NbmGO}$ are characterized by a significant decrease in the ORR overvoltage and higher $n$ values as compared to glassy carbon. This is an indicator of a high concentration of active centers for the adsorption of both oxygen molecules on the surface of bmGO and NbmGO and intermediates of its reduction, which can be surface defects and edge regions of graphene-like structures [34], quinone groups [35], and pyridine nitrogen atoms in the case of the NbmGO sample [27,36], as shown earlier [37].

In addition to high catalytic performance, the ideal electrode material should have excellent long-term stability, which can be evaluated by prolonged chronoamperometry. A chronoamperometry test for the NbmGO catalyst was carried out at $2000 \mathrm{rpm}$ in $\mathrm{O}_{2}$-saturated $0.1 \mathrm{M} \mathrm{KOH}$ solution (see Figure S5 in the Supplementary Materials). The high current retention of $93 \%$ after continuous polarization at $-250 \mathrm{mV}$ during 720 min clearly demonstrates the excellent stability of NbmGO.

\section{Conclusions}

The present work reports on a simple solid-phase method for the synthesis of an effective metal-free electrocatalyst for the oxygen reduction reaction from inexpensive industrial materials, namely, graphene oxide, and melamine. Our method allows the doping of graphene structures with nitrogen atoms and obtaining highly dispersed materials with increased effective electrode surfaces accessible by electrolytes. For the material obtained, a decrease in the ORR overvoltage and an increase in the contribution of the complete reduction of oxygen to water compared to those for glassy carbon are shown. The observed catalytic activity is determined by the high concentration of active sites for adsorption of oxygen molecules and intermediate intermediates of its reduction. The NbmGO long-term stability can be attributed to a small loss of active sites during the test.

Supplementary Materials: The following supporting information can be downloaded at: https: / /www.mdpi.com/article/10.3390/ma15030821/s1, Figure S1: XPS survey spectra of the GO, bmGO, and NbmGO samples, Table S1. Elemental composition (in at.\%) of the samples under study; Figure S2: The conductivity of GO, bmGO, and NbmGO films at different $\mathrm{RH} \%$; Figure S3: A model structure of NbmGO; Figure S4: Electronic absorption spectra of GO, bmGO and NbmGO films (quartz glass). The maximum of the electronic absorption spectrum shifts to shorter wavelengths $(224 \mathrm{~nm} \rightarrow 205 \mathrm{~nm}$ ) for the samples of GO, bmGO and NbmGO and there is an increase in absorption observed in the range $400-800 \mathrm{~nm}$, which is typical for $s p^{2}$-carbon; Table S2: Positions $\left(E_{\mathrm{b}}\right)$, full widths at half maximum ( $F W H M$ ), and intensities (Int) of the peaks in the XPS spectra of the GO, bmGO and NbmGO samples; Table S3: The characteristic features in the FTIR spectra of GO and melamine; Table S4: Peak positions and the band intensity ratios $\left(I_{\mathrm{D}} / I_{\mathrm{G}}\right)$ in the Raman spectra of graphite, GO, bmGO, and NbmGO; Table S5: ESR data obtained for samples of GO, bmGO, and NbmGO at room temperature; Table S6: Electrochemical properties of N-doped carbon materials; Figure S5: Long-term stability of $\mathrm{NbmGO}$ via chronoamperometry test at $-300 \mathrm{mV}$ in $0.1 \mathrm{M} \mathrm{KOH}$ and at room temperature, $\omega=2000 \mathrm{rpm}$.

Author Contributions: Investigation, formal analysis, writing—original draft, project administration, V.P.V.; Investigation, writing, review and editing, R.A.M.; Investigation, V.K.K.; Writing, review, and editing, A.G.K.; Formal analysis, E.N.K.; Investigation, formal analysis, A.V.K.; Review and editing, project administration, Y.M.S.; Review and editing, data curation, G.L.G. All authors have read and agreed to the published version of the manuscript.

Funding: The study was performed in accordance with the State Assignments NosAAAA-A19119032690060-9 and AAAA-A19-119061890019-5.

Institutional Review Board Statement: Not applicable.

Informed Consent Statement: Not applicable.

Data Availability Statement: Data available in a publicly accessible repository. 
Acknowledgments: The work used the equipment of the Multi-User Analytical Center of IPCP RAS, and the Chernogolovka Scientific Center RAS.

Conflicts of Interest: The authors declare no conflict of interest.

\section{References}

1. Shao, M.H.; Chang, Q.W.; Dodelet, J.-P.; Chenitz, R. Recent advances in electrocatalysts for oxygen reduction reaction. Chem. Rev. 2016, 116, 3594-3657. [CrossRef] [PubMed]

2. Majlan, E.H.; Rohendi, D.; Daud, W.R.W.; Husaini, T.; Haque, M.A. Electrode for proton exchange membrane fuel cells: A review. Renew. Sustain. Energy Rev. 2018, 89, 117-134. [CrossRef]

3. Shao, Q.; Li, F.M.; Chen, Y.; Huang, X.Q. The advanced designs of high-performance platinum-based electrocatalysts: Recent progresses and challenges. Adv. Mater. Interfaces 2018, 5, 1800486. [CrossRef]

4. Gasteiger, H.A.; Kocha, S.S.; Sompalli, B.; Wagner, F.T. Activity benchmarks and requirements for Pt, Pt-alloy, and non-Pt oxygen reduction catalysts for PEMFCs. Appl. Catal. B Environ. 2005, 56, 9-35. [CrossRef]

5. Nørskov, J.K.; Rossmeisl, J.; Logadottir, A.; Lindqvist, L.; Kitchin, J.R.; Bligaard, T.; Jónsson, H. Origin of the overpotential for oxygen reduction at a fuel-cell cathode. J. Phys. Chem. B 2004, 108, 17886-17892. [CrossRef]

6. Greeley, J.; Stephens, I.E.L.; Bondarenko, A.S.; Johansson, T.P.; Hansen, H.A.; Jaramillo, T.F.; Rossmeisl, J.; Chorkendorff, I.; Norskøv, J.K. Alloys of platinum and early transition metals as oxygen reduction electrocatalysts. Nat. Chem. 2009, 1, 552-556. [CrossRef] [PubMed]

7. Wang, Y.; Shao, Y.Y.; Matson, D.W.; Li, J.H.; Lin, Y.H. Nitrogen-doped graphene and its application in electrochemical biosensing. ACS Nano 2010, 4, 1790-1798. [CrossRef]

8. Daems, N.; Sheng, X.; Vankelecom, I.F.J.; Pescarmona, P.P. Metal-free doped carbon materials as electrocatalysts for the oxygen reduction reaction. J. Mater. Chem. A 2014, 2, 4085-4110. [CrossRef]

9. Qu, L.T.; Liu, Y.; Baek, J.B.; Dai, L.M. Nitrogen-doped graphene as efficient metal-free electrocatalyst for oxygen reductionin fuel cells. ACS Nano 2010, 4, 1321-1326. [CrossRef]

10. Gong, K.P.; Du, F.; Xia, Z.H.; Durstock, M.; Dai, L.M. Nitrogen doped carbon nanotube arrays with high electrocatalytic activity for oxygen reduction. Science 2009, 323, 760-764. [CrossRef]

11. Kakaei, K.; Ghadimi, G. A green method for nitrogen-doped graphene and its application for oxygen reduction reaction in alkaline media. Mater. Technol. 2020, 36, 46-53. [CrossRef]

12. Sheng, Z.-H.; Shao, L.; Chen, J.-J.; Bao, W.-J.; Wang, F.-B.; Xia, X.-H. Catalyst-free synthesis of nitrogen-doped graphene via thermal annealing graphite oxide with melamine and its excellent electrocatalysis. ACS Nano 2011, 5, 4350-4358. [CrossRef] [PubMed]

13. Jukk, K.; Kongi, N.; Tammeveski, K.; Arán-Ais, R.M.; Solla-Gullón, J.; Feliu, J.M. Loading effect of carbon-supported platinum nanocubes on oxygen electroreduction. Electrochim. Acta 2017, 251, 155-166. [CrossRef]

14. Gómez-Marín, A.M.; Feliu, J.M.; Ticianelli, E. Oxygen reduction on platinum surfaces in acid media: Experimental evidence of a CECE/DISP initial reaction path. ACS Catal. 2019, 9, 2238-2251. [CrossRef]

15. Manzhos, R.A.; Baskakov, S.A.; Kabachkov, E.N.; Korepanov, V.I.; Dremova, N.N.; Baskakova, Y.V.; Krivenko, A.G.; Shulga, Y.M.; Gutsev, G.L. Reduced graphene oxide aerogel inside melamine sponge as an electrocatalyst for the oxygen reduction reaction. Materials 2021, 14, 322. [CrossRef] [PubMed]

16. Leo, V.; Rodriguez, A.M.; Prieto, P.; Prato, M.; Vazquez, E. Exfoliation of graphite with triazine derivatives under ball-milling conditions: Preparation of few-layer graphene via selective noncovalent interactions. ACS Nano 2014, 8, 563-571.

17. Venkatachalam, P.; Ganesan, S.; Rengapillai, S.; Vembu, S.; Sivakumar, M. Physicochemical exfoliation of graphene sheet using graphitic carbon nitride. New J. Chem. 2019, 43, 16200-16206.

18. Ahmad, J.; Sofi, F.A.; Mehraj, O.; Majid, K. Fabrication of highly photocatalytic active anatase $\mathrm{TiO}_{2}$-graphene oxide heterostructures via solid phase ball milling for environmental remediation. Surf. Interfaces 2018, 13, 186-195. [CrossRef]

19. Kahimbi, H.; Hong, S.B.; Yang, M.; Choi, B.G. Simultaneous synthesis of NiO/reduced graphene oxide composites by ball milling using bulk Ni and graphite oxide for supercapacitor applications. J. Electroanal. Chem. 2017, 786, 14-19.

20. Hummers, W.S.; Offeman, R.E. Preparation of Graphitic Oxide. J. Am. Chem. Soc. 1958, 80, 1339.

21. Bard, A.J.; Faulkner, L.R. Electrochemical Methods: Fundamentals and Applications, 2nd ed.; Wiley: New York, NY, USA, 2001.

22. Jürmann, G.; Tammeveski, K. Electroreduction of oxygen on multi-walled carbon nanotubes modified highly oriented pyrolytic graphite electrodes in alkaline solution. J. Electroanal. Chem. 2006, 597, 119-126. [CrossRef]

23. Hanifah, M.F.R.; Jaafar, J.; Aziz, M.; Ismail, A.F.; Othman, M.H.D.; Rahman, M.A.; Norddin, M.N.A.M.; Yusof, N.; Salleh, W.N.W. Efficient reduction of graphene oxide nanosheets using $\mathrm{Na}_{2} \mathrm{C}_{2} \mathrm{O}_{4}$ as a reducing agent. Funct. Mater. Lett. 2015, 8, 155026. [CrossRef]

24. Lesiak, B.; Kövér, L.; Tóth, J.; Zemek, J.; Jiricek, P.; Kromka, A.; Rangam, N. C sp ${ }^{2} / \mathrm{sp}^{3}$ hybridisations in carbon nanomaterialsXPS and (X) AES study. Appl. Surf. Sci. 2018, 452, 223-231. [CrossRef]

25. Lazar, P.; Mach, R.; Otyepka, M. Spectroscopic fingerprints of graphitic, pyrrolic, pyridinic, and chemisorbed nitrogen in N-doped graphene. J. Phys. Chem. C 2019, 123, 10695-10702. [CrossRef] 
26. Mondal, O.; Mitra, S.; Pal, M.; Datta, A.; Dhara, S.; Chakravorty, D. Reduced graphene oxide synthesis by high energy ball milling. Mater. Chem. Phys. 2015, 161, 123-129. [CrossRef]

27. Guo, D.; Shibuya, R.; Akiba, C.; Saji, S.; Kondo, T.; Nakamura, J. Active sites of nitrogen-doped carbon materials for oxygen reduction reaction clarified using model catalysts. Science 2016, 351, 361-365. [CrossRef]

28. Hanifah, M.F.R.; Jaafar, J.; Othman, M.H.D.; Ismail, A.F.; Rahman, M.A.; Yusof, N.; Salleh, W.N.W.; Aziz, F. Facile synthesis of highly favorable graphene oxide: Effect of oxidation degree on the structural, morphological, thermal and electrochemical properties. Materialia 2019, 6, 100344. [CrossRef]

29. Calizo, I.; Balandin, A.A.; Bao, W.; Miao, F.; Lau, C.N. Temperature dependence of the Raman spectra of graphene and graphene multilayers. Nano Lett. 2007, 7, 2645-2649. [CrossRef]

30. Fu, J.; Wei, C.; Wang, W.; Wei, J.L.; Lu, J. Studies of structure and properties of graphene oxide prepared by ball milling. Mater. Res. Innov. 2015, 19, S1-277-S1-280. [CrossRef]

31. Pimenta, M.A.; Dresselhaus, G.; Dresselhaus, M.S.; Cançado, L.G.; Jorio, A.; Saito, R. Studying disorder in graphite-based systems by Raman spectroscopy. Phys. Chem. Chem. Phys. 2007, 9, 1276-1290. [CrossRef]

32. Dvoranova, D.; Barbierikova, Z.; Mazur, M.; Garcia-Lopez, E.I.; Marci, G.; Luspai, K.; Brezova, V. EPR investigations of polymeric and $\mathrm{H}_{2} \mathrm{O}_{2}$-modified $\mathrm{C}_{3} \mathrm{~N}_{4}$-based photocatalysts. J. Photochem. Photobiol. A 2019, 375, 100-113. [CrossRef]

33. Di, J.; Xia, J.X.; Li, X.W.; Ji, M.X.; Xu, H.; Chen, Z.G.; Li, H.M. Constructing confined surface carbon defects in ultrathin graphitic carbon nitride for photocatalytic free radical manipulation. Carbon 2016, 107, 1-10. [CrossRef]

34. Shen, A.L.; Zou, Y.Q.; Wang, Q.; Dryfe, R.A.W.; Huang, X.B.; Dou, S.; Dai, L.M.; Wang, S.Y. Oxygen reduction reaction in a droplet on graphite: Direct evidence that the edge is more active than the basal plane. Angew. Chem. Int. Ed. 2014, 53, 10804-10808. [CrossRef] [PubMed]

35. Vasiliev, V.P.; Kotkin, A.S.; Kochergin, V.K.; Manzhos, R.A.; Krivenko, A.G. Oxygen reduction reaction at few-layer graphene structures obtained via plasma-assisted electrochemical exfoliation of graphite. J. Electroanal. Chem. 2019, 851, 113440. [CrossRef]

36. Lai, L.F.; Potts, J.R.; Zhan, D.; Wang, L.; Poh, C.K.; Tang, C.H.; Gong, H.; Shen, Z.X.; Jianyi, L.Y.; Ruoff, R.S. Exploration of the active center structure of nitrogen-doped graphene-based catalysts for oxygen reduction reaction. Energy Environ. Sci. 2012, 5, 7936-7942. [CrossRef]

37. Vasiliev, V.P.; Manzhos, R.A.; Krivenko, A.G.; Kabachkov, E.N.; Shulga, Y.M. Nitrogen-enriched carbon powder prepared by ball-milling of graphene oxide with melamine: An efficient electrocatalyst for oxygen reduction reaction. Mendeleev Commun. 2021, 31, 529-531. [CrossRef] 